\title{
Schistosomiasis in immigrants, refugees and travellers in an Italian referral centre for tropical diseases
}

\author{
Valentina Marchese ${ }^{1,2}$, Anna Beltrame ${ }^{1 *}$, Andrea Angheben', Geraldo Badona Monteiro', Giovanni Giorli',
} Francesca Perandin ${ }^{1}$, Dora Buonfrate ${ }^{1}$ and Zeno Bisoffi ${ }^{1}$

\begin{abstract}
Background: Schistosomiasis is one of the most important neglected tropical diseases. If unrecognised and untreated, the chronic infection can lead to irreversible complications.

Methods: Retrospective observational study aimed at describing clinical history, laboratory findings and imaging presentation of imported schistosomiasis diagnosed at the Centre for Tropical Diseases, Sacro Cuore Don Calabria Hospital of Negrar, Verona, Italy from 2010 to 2014. The aim of our study was to assess differences in demographic characteristics, clinical presentation, laboratory data and ultrasound findings between immigrants/visiting friends and relatives (VFR) from endemic countries (endemic group) and expatriates/travellers (non-endemic group).

Results: A total of 272 patients were retrieved: 234 in the endemic and 38 in the non-endemic group. Most of the patients acquired schistosomiasis in Africa (97.4\%). Symptoms were reported by $52.9 \%$ of the patients; abdominal pain (36\%), macroscopic hematuria (11.3\%), and genito-urinary symptoms (7.4\%) being the most frequently reported. Increased IgE and blood eosinophilia were observed in 169 (63.8\%) and 130 (47.8\%) patients, respectively. The proportion of positive serology was 250/272 (91.9\%).The Circulating Cathodic Antigen CCA for Schistosoma mansoni was positive in 14/61 individuals (23\%). At microscopy, infected subjects were 103/272 (37.9\%). The species of Schistosoma found were S. haematobium (47.6\%), S. mansoni (46.6\%) or both (5.8\%). Schistosomiasis was classified as confirmed in 103 (37.9\%), probable in 165 (60.6\%) and suspected in 4 (1.5\%) cases using clinical presentation, laboratory data and ultrasound findings. The infection was further classified based on organ involvement: intestinal (17.9\%), hepatosplenic (5.1\%), urogenital (48.9\%), and indeterminate (43.8\%).

The comparative analysis of endemic and non-endemic patients highlighted differences in sex and age. Endemic patients had more frequent ova identification $(41.9 \%$ vs. $13.2 \%, P<0.001)$ and increased lgE $(70 \%$ vs. $26.3 \%$, $P<0.001)$ when compared with non-endemic. Multivariate analyses showed that younger age, abnormal ultrasound findings and blood eosinophilia were significantly associated with positive microscopy $(O R=0.94, O R=2.12$, $O R=1.98$, respectively).

Conclusions: Symptoms, eosinophilia and abnormal ultrasound findings were present in about half of patients, without differences between groups. Many patients had positive serology but negative microscopy, indicating that schistosomiasis might be misdiagnosed. A combination of diagnostic tools may facilitate the diagnosis.
\end{abstract}

Keywords: Schistosomiasis, Neglected tropical diseases, immigrants, Refugees, Travellers, Europe, Italy

\footnotetext{
* Correspondence: anna.beltrame@sacrocuore.it

${ }^{1}$ Centre for Tropical Diseases, Sacro Cuore Don Calabria Hospital, Via

Sempreboni 5, 37024 Negrar, Italy

Full list of author information is available at the end of the article
}

C The Author(s). 2018 Open Access This article is distributed under the terms of the Creative Commons Attribution 4.0 International License (http://creativecommons.org/licenses/by/4.0/), which permits unrestricted use, distribution, and reproduction in any medium, provided you give appropriate credit to the original author(s) and the source, provide a link to the Creative Commons license, and indicate if changes were made. The Creative Commons Public Domain Dedication waiver (http://creativecommons.org/publicdomain/zero/1.0/) applies to the data made available in this article, unless otherwise stated. 


\section{Multilingual abstracts}

Please see Additional file 1 for translations of the abstract into the five official working languages of the United Nations.

\section{Background}

Schistosomiasis is one of the most important neglected tropical diseases (NTDs), affecting over 258 million people in 78 countries and causing 3.3 million disability-adjusted life-years (DALYs) [1-4]. In sub-Saharan Africa, where around $90 \%$ of the global cases occur, approximately 300000 deaths annually have been estimated to be caused by schistosomiasis [5].

Schistosoma mansoni and S. haematobium, the predominating human species, cause intestinal schistosomiasis (IS), hepatosplenic schistosomiasis (HSS) and urogenital schistosomiasis (UGS), respectively [1, 6]. Infections caused by $S$. intercalatum, S. japonicum and S. mekongi are rarely reported, the latter two restricted to Asia [7].

People born in endemic countries are at high risk of acquiring the infection during childhood, by contact with contaminated freshwater. The exposure continues in later years during domestic, recreational and economic activities $[1,6]$. As the lifetime of the adult Schistosoma ranges from three to 40 years [8, 9], chronic Schistosoma infections may remain clinically silent (30-50\% of the cases) [10] or cause relatively mild and non-specific symptoms for years before eventually causing severe, often unrecoverable organ damage such as fibrosis and portal hypertension for $S$. mansoni, and obstructive uropathy and hydronephrosis for S. haematobium [11-13]. Interestingly, the latter may lead to squamous cell carcinoma of the bladder $[14,15]$. However, as clearly highlighted by King [16], schistosomiasis should never be considered a benign asymptomatic infection, as it always leads to chronic tissue inflammation when left untreated. Unfortunately, low-intensity infections may be easily missed by the most widely available diagnostic test, that is microscopy.

Europe, and Italy in particular, is receiving an unprecedented flow of immigrants from sub-Saharan Africa, many asylum seekers [17]. According to GeoSentinel [a network of 41 tropical and travel medicine centres in 19 countries around the world (http://www.istm.org/geosentinel)] from 1997 to 2009, schistosomiasis was diagnosed in 442 of 7629 (5.8\%) migrants, predominantly non-refugees, $84 \%$ of whom acquired the infection in Africa [18]. In these last years, schistosomiasis prevalence among African refugees and asylum seekers has been striking, albeit mostly unrecognized as sensitive screening tools are generally unavailable [19-26].

Sub-Saharan Africa is a frequent destination reported by European travellers [27]. In the EuroTravNet network of 18 European specialized centres (http://www.eurotravnet.eu), which reported the travel-related illnesses of 32136 travellers from 2008 to 2012, schistosomiasis ranked 12th with only 152 cases recorded [27]. Nevertheless, the risk of schistosomiasis is not negligible in this group; often after a single brief exposure to contaminated freshwater [28, 29]. Several cases series of schistosomiasis in European travellers have been reported in recent years [30-36].

An unexpected outbreak of autochthonous urogenital schistosomiasis cases occurred in Corsica, France during the period 2013-2015 [37, 38], caused by a parasite genetically related to $S$. haematobium from Senegal $[39,40]$. The outbreak raised attention to a possible spread of schistosomiasis in areas of Southern Europe [41-43] where the intermediate host is present [44]. Hence, surveillance on imported schistosomiasis in Europe, together with an increased professional awareness for this NTD, are necessary [45].

This study reviews demographic data, travel history, clinical and laboratory information, imaging and other diagnostic findings of the largest case series of imported schistosomiasis observed in a single site (the Centre for Tropical Diseases, [CTD] Sacro Cuore Don Calabria Hospital, Negrar, Verona) in Italy over a 5-year period.

\section{Methods \\ Study design}

Retrospective, observational study intended to review patients diagnosed with schistosomiasis at CTD and to assess differences between subjects born in endemic and non-endemic countries.

\section{Study population and data collection}

The study was carried out at the CTD, a national referral centre for tropical and parasitic diseases, between 1 January 2010 and 31 December 2014. Patients were included in the study if they met diagnostic criteria for schistosomiasis, described in the case definition paragraph. All patients were treated with praziquantel $40 \mathrm{mg} / \mathrm{kg}$ for three consecutive days. Patients lacking a written informed consent for collection of data and biological samples for study purposes were excluded from the study.

For each included patient, we reviewed from a CTD patient database the travel history, clinical and laboratory data, imaging, and other diagnostic procedure findings. Data were analysed anonymously.

The study subjects were classified into two groups:

Endemic group: immigrants from countries where schistosomiasis is endemic, differentiated into either immigrants, refugees or asylum seekers recently arrived in Italy, or non-recent immigrants who had travelled to their countries of origin for business purpose or visiting friends or relatives (VFR);

Non-endemic group: Italians visiting endemic countries, including expatriates and short-term travellers (tourists, students, business travellers). 
For the endemic group, the country of origin was recorded as the probable area of exposure. The period of time going from the date of first arrival in Italy to the date of diagnosis was defined as "elapsed time". For the non-endemic group, the country visited and the elapsed time (days from the date of return to the date of diagnosis) were recorded. If the patient reported possible exposure in more than one endemic area for schistosomiasis, the country of the longer exposure was selected, unless there were clear indications for acquisition of the infection in a different country.

The symptoms and signs included were abdominal pain, defined as non-specific abdominal discomfort and pain, and genito-urinary symptoms, comprehensive of urinary frequency, dysuria and/or burning and/or painful ejaculation. Additionally, Katayama syndrome, cough and gynaecological/andrological complaints were classified as other symptoms, while the presence of blood in urine or stool was recorded as macrohematuria or rectal bleeding, respectively.

\section{Laboratory data}

The blood test evaluation of each patient included blood cell count and IgE quantitative nephelometry assay. Blood eosinophilia was defined in case of absolute eosinophil count (AEC) value $\geq 300 \mathrm{cell} / \mu \mathrm{l}$ and increased IgE if total IgE value equal or above the upper normal limit ( $\geq 120 \mathrm{IU} / \mathrm{ml}$ ).

Serum samples were evaluated for the detection of antibodies against Schistosoma spp. by an indirect immunofluorescence (IFAT) using whole cercarial antigen (DiaTeSt-Cercaria FAT) from January 2010 to September 2012. An Enzyme-linked immunosorbent assay (ELISA) using S. mansoni soluble egg antigens (Bordier Affinity Products, Crissier, Switzerland) was introduced from February 2012 to December 2014. Other immunodiagnostic methods were used to detect the presence of Strongyloides stercoralis and viral infections: an in-house indirect immunofluorescence (IFAT) for S. stercoralis [46] and enzyme-linked immunosorbent assay (ELISA, Beckmann) for HIV, HCV and HBsAg with a confirmatory test in case of a positive result.

Finally, since March 2014, urine circulating cathodic antigen (CCA) dipstick test for S. mansoni was available: from a single urine sample a $50 \mu \mathrm{l}$ aliquot was used to test for the presence of schistosoma CCA with a commercially available immuno-chromatographic dipstick test following the manufacturer's instruction (NADAL CCA Bilharzia test, Germany).

Microscopy examination $(100 \times)$ for ova and parasites, after formol-ether concentration on three stool samples collected in alternate days was performed for each patient together with an urine microscopy examination $(100 \times)$ after micropore filtration for S. haematobium on the sediment of at least $20 \mathrm{ml}$ end-stream urine. One to three urine samples were obtained from 10 am to 12 am over consecutive days. Microscopy detection of eggs in biopsy of any tissue specimen was also performed, if done.

\section{Ultrasounds and other diagnostic procedures}

The results of abdomen ultrasounds and other invasive tests, such as liver biopsy, were recorded. In particular, an ultrasound finding was considered abnormal in the case of: liver or spleen enlargement (a rounding of the inferior liver margin, and bipolar spleen diameter $>12 \mathrm{~cm}$ ), periportal thickening, cirrhosis, portal hypertension, bladder wall thickening or lesions (calcification or small parietal vegetation), an abnormality in the urinary tract (ureter dilatation or hydronephrosis) or lesions compatible with liver or bladder cancer [47-49].

Two abnormal ultrasound patterns that likely correlated to the schistosomiasis were recorded:

Urogenital (UG) pattern: bladder wall thickening or lesions, an abnormality of the urinary tract or lesions compatible with bladder cancer.

Hepatosplenic (HS) pattern: presence of periportal thickening, cirrhosis or portal hypertension.

\section{Case definition}

Based on clinical, laboratory, and ultrasounds findings, we operationally classified schistosomiasis as [32, 37] confirmed schistosomiasis in case of retrieval of Schistosoma ova (either in stool, urine or specimen biopsy). Whenever a patient had positive urine CCA and/or serology test without evidence of ova, the case was classified as having probable schistosomiasis. A possible schistosomiasis was defined with abnormal ultrasound patterns (as defined previously) and/or total $\mathrm{IgE} \geq 1000 \mathrm{IU} / \mathrm{ml}$, without evidence of ova or with negative urine CCA or serology test [32].

Additionally, based on signs of organ involvement, we differentiated schistosomiasis into intestinal schistosomiasis (IS) if ova of S. mansoni or S. mekongi or S. japonicum were found in the stool or in the rectal biopsy. If ova of S. mansoni or S. mekongi or S. japonicum were found in the liver biopsy or if the ultrasounds revealed an HS pattern (as defined above) the case was considered as hepatosplenic schistosomiasis (HSS). Urogenital schistosomiasis (UGS) was diagnosed if ova of $S$. haematobium were found in the urine or bladder biopsy, if the patient reported macroscopic hematuria or genito-urinary symptoms or if the ultrasound revealed a UG pattern (as defined above). In absence of ova, positive serology and/or urine CCA test, and without any ultrasound patterns or specific symptoms, the patient was considered having indeterminate schistosomiasi (I).

\section{Statistical analysis}

Descriptive statistics were used to analyse the characteristics of the entire cohort and then separately for 
individuals born in endemic areas and individuals born in Italy. Categorical variables were reported as frequencies and proportions, while quantitative variables were presented as median (inter-quartile range, IQR).

The association between the aforementioned variables was then investigated through univariate statistical tests, such as the Chi-squared test, Fisher test and Kolmogorov-Smirnov test, as considered appropriate. Lastly, multivariate logistic regression models were fitted to assess the impact of all covariates on the probability of contracting symptoms related to schistosomiasis and on the probability of detecting ova in any specimen. All statistical analyses were conducted using $\mathrm{R}$, version 3.3.3 [50].

\section{Results}

\section{Demographic data and travel history}

Demographic data and travel-related information are detailed in Table 1. Of the 272 subjects, 215 (79\%) were male and the median age was 30 (IQR:25-39.5). Most subjects (86\%) were immigrants, of whom, 76.1\% (178 subjects) were either refugees or asylum seekers, whereas in the non-endemic group (38 subjects) travellers and expatriates were equally represented (19 subjects in both sub-groups). The male gender was more represented in the immigrant group than in the travellers of the non-endemic group ( 82.5 vs $57.9 \%, P=0.002)$. The median age of the immigrants was significantly lower than that of the patients in the non-endemic group ( 28 vs 41.5 years, $P<0.001$ ).

Almost all cases originated from Africa $(n=261,97.4 \%)$, mostly Western $(n=188,69.1 \%)$, Eastern $(n=41,15.1 \%)$ and Central $(n=29,10.7 \%)$; only a few cases were from South America $(n=4,1.5 \%)$, Asia and Oceania $(n=3,1 \%)$. The most represented countries (not reported in Table) were Mali (19\%), Ghana (14\%), Ivory Coast (7\%), Senegal (6\%), Nigeria (5\%), Tanzania (5\%) and Ethiopia (4\%). The countries of probable exposure are shown in detail in Fig. 1. The median elapsed time was 197 (67.5-526.5) days.

\section{Clinical presentation and laboratory characteristics}

One hundred and forty-four (52.9\%) patients presented at least one symptom suggestive of schistosomiasis (Table 2). The most common symptom was abdominal pain (36\%), followed by macroscopic hematuria (11.3\%), other genito-urinary symptoms (7.4\%), rectal bleeding $(1.5 \%)$, and cough $(1.1 \%)$. None of the patients were diagnosed with Katayama syndrome. No significant differences were found in the symptom distribution between the two main groups.

HIV infection ( $n=4,1.5 \%)$, chronic hepatitis B $(n=36,13.2 \%)$, and HCV infection $(n=8,2.9 \%)$ were exclusively found in the endemic group. One patient had the co-infection schistosomiasis/HCV/HBV.

Forty-nine subjects (22.8\%) had other helminth infections, including both $S$. stercoralis diagnosed by immunodiagnostic method, as well as other intestinal helminths, diagnosed by parasitological method.

The median value of $\operatorname{IgE}$ and absolute eosinophil count were $304.5 \mathrm{IU} / \mathrm{ml}$ (IQR: 52.5-924.5) and $290 \mathrm{cell} / \mu \mathrm{l}$ (IQR: 160-540), respectively. Increased IgE was observed in 169 subjects (63.8\%), while peripheral eosinophilia was present in $130(47.8 \%)$ patients. The IgE level was more frequently raised in the endemic group (70 vs. $26.3 \%$, $P<0.001$ ), while no significant difference was found in the proportion of eosinophilia.

Schistosoma ova were detected in 103 subjects (37.9\%): S. haematobium in 49 (47.6\%), S. mansoni in 48 (46.6\%) and both species in 6 subjects (5.8\%). The ova were found in stools in 50 cases (18.4\%), urine in 52 (19.1\%), and tissue biopsy in $12(4.4 \%)$, specifically: lungs $(n=2)$, liver $(n=2)$, uterus $(n=1)$, colon $(n=1)$ and appendix $(n=1)$. The immigrants were more likely to have ova detected than the non-endemic subjects $(41.9$ vs. $13.2 \%$, $P<0.001)$.

Serology for schistosomiasis was positive in 250 subjects $(91.9 \%)$ with no significant differences between the

Table 1 Baseline demographic of the cohort and stratified by endemicity of provenience

\begin{tabular}{|c|c|c|c|c|}
\hline \multirow[t]{2}{*}{ Characteristic $^{a}$} & \multirow{2}{*}{$\begin{array}{l}\text { Entire cohort } \\
N, \%\end{array}$} & \multicolumn{2}{|l|}{ Area of origin } & \multirow[t]{2}{*}{$p$-value ${ }^{b}$} \\
\hline & & Endemic & Non-endemic & \\
\hline Total & 272 & $234(86.0)$ & $38(14.0)$ & \\
\hline Median age, years (IQR) & $30(25-39.5)$ & $28(24-38)$ & $41.5(34-63.7)$ & $<0.001^{*}$ \\
\hline Male, $N(\%)$ & $215(79.0)$ & $193(82.5)$ & $22(57.9)$ & $0.002^{*}$ \\
\hline Median elapsed time, days (IQR) & $197(67.5-526.5)$ & $209(71-576.5)$ & $120.5(52-392.7)$ & 0.327 \\
\hline \multicolumn{5}{|l|}{ Continent of Exposure, N (\%) } \\
\hline Africa & $261(97.4)$ & $232(99.1)$ & $29(85.3)$ & $<0.001^{*}$ \\
\hline America & $4(1.5)$ & $2(0.9)$ & $2(5.9)$ & 0.089 \\
\hline Asia and Oceania & $3(1.1)$ & $0(0.0)$ & $3(8.8)$ & \\
\hline
\end{tabular}

Abbreviations: IQR Inter-quartile range

${ }^{a}$ Relative frequencies for each variable are obtained on the sub-population for which information was available

${ }^{b}$ Calculation of the $P$-value was done through Kolmogorov-Smirnov test for the difference in the distribution of age and elapsed time, whereas Fisher's exact test

was used for all dichotomous variables. Finally, the Chi-Squared test was used to test the difference in the distribution among diagnoses types 


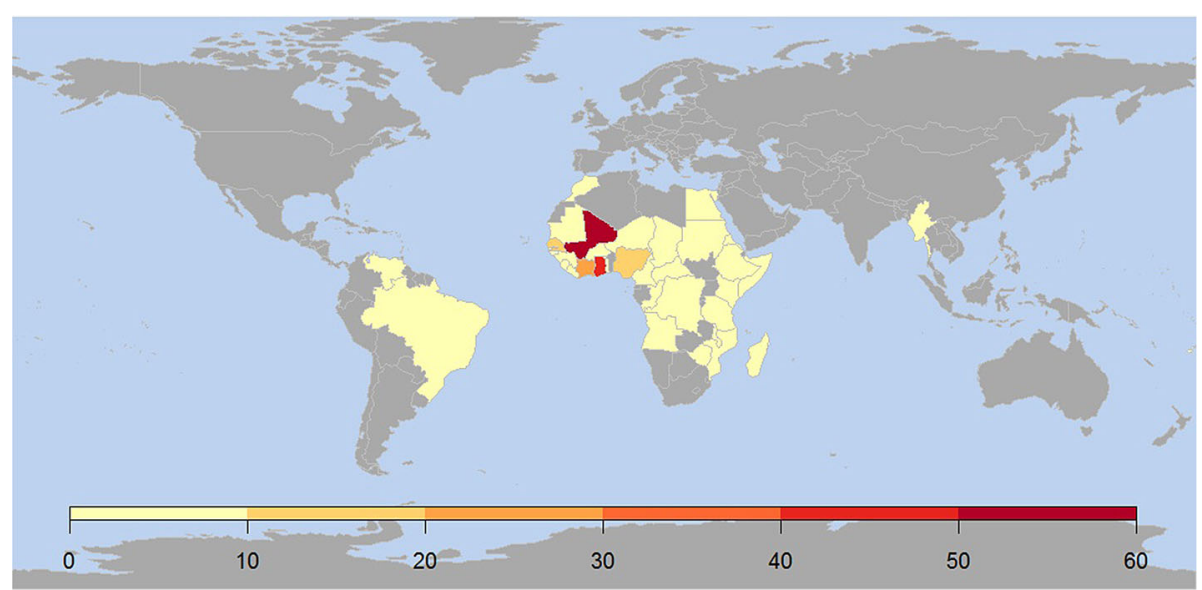

Fig. 1 Geographical distribution of the places of exposure (data are the number of patients)

groups. IFAT serology was used in 163 cases (59.9\%), while 109 patients $(40.1 \%)$ were tested by ELISA test.

Eighteen of 103 patients (17.5\%) with schistosoma ova identified by microscopy were negative by serology. Eleven of these 18 patients (61.1\%) had S. haematobium infection.

Urine CCA test was found positive in 14 of 61 (23\%) patients evaluated with this test.

\section{Ultrasound findings and patterns}

Ultrasounds showed abnormalities in 124 of 254 subjects examined (48.8\%), including: liver enlargement ( $n=64,25.2 \%)$, spleen enlargement $(n=35,13.8 \%)$, cirrhosis $(n=8,3.2 \%)$, bladder lesions $(n=22,8.7 \%)$ (Fig. 2$)$, thick bladder wall $(n=45,17.7 \%)$, portal hypertension ( $n=6,2.4 \%)$ and periportal thickening/fibrosis $(n=6,2.4 \%)$. In summary, $52(20.5 \%)$ patients' ultrasound findings were compatible with the UG pattern and 13 (5\%) with the HS pattern, without differences between the groups (data not shown).

Thirty-six of 103 (34.9\%) patients with schistosomiasis confirmed by microscopy had an abnormal ultrasound pattern: 30 (29.1\%) UG, three (2.9\%) HS, and three patients $(2.9 \%)$ both patterns. Differently, in patients with schistosomiasis with positive serology test without evidence of ova, 21 (12.7\%) had ultrasound alterations: five (3\%) HS and 16 (9.7\%) UG pattern.

Globally, rates of ultrasound abnormalities found in confirmed schistosomiasis and in patients with positive serology only (34.9\% vs. $12.7 \%)$ were statistically different $(P<0.001)$.

\section{Case definition}

According to the clinical features, the patients were classified as follows: 133 (48.9\%) with UGS, 48 (17.9\%) with IS, 13 (5.1\%) with HSS and 110 (43.8\%) with indeterminate schistosomiasis. The diagnosis was confirmed in 103 cases $(37.9 \%)$, probable in $165(60.6 \%)$, and possible in four (1.5\%) (Table 2).

\section{Univariate and multivariate analyses}

Table 3 shows the results of the univariate and multivariate analyses on the association between microscopic ova identification and demographic characteristics, as well as laboratory/ultrasound findings. Younger age, abnormal ultrasound findings and blood eosinophilia were significantly associated with a positive microscopy $(O R=0.94, \quad 95 \% \quad C I: 0.91-0.97 ; \quad O R=2.12, \quad 95 \% \quad C I$ : 1.15-3.96; $O R=1.98,95 \% C I: 1.03-3.83$, respectively).

\section{Discussion}

Sentinel surveillance data for imported schistosomiasis in Europe has been available since 1997 through the European Network for Tropical Medicine and Travel Health (TropNet) $[32,36]$ and the GeoSentinel Surveillance Network [34]. Moreover, a few observational studies were performed by individual tropical centres in Munich (Germany) [30], Barcelona (Spain) [31], Amsterdam (the Netherlands) [33] and London (United Kingdom) [35].

Most of our cases (96\%) were imported from the African continent, primarily West Africa, similarly to all studies mentioned above [30-36]. A peculiarity of our study is the high proportion of migrants (86\%), of whom more than two-thirds were young male refugees and asylum seekers (all from Africa), in contrast with travellers and expatriates. The recent high flow of asylum seekers from Africa to Europe (and particularly to Italy) largely explains the demographic characteristics observed [17].

Previous screening studies conducted on migrant populations in Europe found a questionably low prevalence of schistosomiasis, probably depending on the diagnostic tools used [19, 21, 23-25]. Indeed, only about $40 \%$ of our patients included in the endemic group had a diagnosis of confirmed schistosomiasis, and therefore, had 
Table 2 Clinical characteristics and laboratory results of the cohort and stratified by endemicity of provenience

\begin{tabular}{|c|c|c|c|c|}
\hline \multirow[t]{2}{*}{ Characteristic $^{a}$} & \multirow[t]{2}{*}{ Entire cohort } & \multicolumn{2}{|c|}{ Area of origin } & \multirow[t]{2}{*}{$p$-value } \\
\hline & & Endemic & Non-endemic & \\
\hline Total, N (\%) & 272 & $234(86.0)$ & $38(14.0)$ & \\
\hline Symptoms presence, $N(\%)$ & $144(52.9)$ & $124(52.9)$ & $20(52.6)$ & 1 \\
\hline Abdominal pain & $98(36.0)$ & $85(36.3)$ & $13(34.2)$ & 0.857 \\
\hline Genito-urinary & $20(7.4)$ & $16(6.8)$ & $4(10.5)$ & 0.625 \\
\hline Macro-hematuria & $25(11.3)$ & $22(9.4)$ & $3(7.9)$ & 1 \\
\hline Rectal bleeding & $4(1.5)$ & $4(1.7)$ & $0(0)$ & \\
\hline Cough & $3(1.1)$ & $3(1.3)$ & $0(0)$ & \\
\hline Positive microscopy, N (\%) & $103(37.9)$ & $98(41.9)$ & $5(13.2)$ & $<0.001^{*}$ \\
\hline Ova in stools & $50(18.4)$ & $48(20.5)$ & $2(5.3)$ & $0.020^{*}$ \\
\hline Ova in urine & $52(19.1)$ & $49(20.9)$ & $3(7.9)$ & 0.070 \\
\hline Ova in biopsy & $12(4.4)$ & $11(4.7)$ & $1(2.6)$ & 1 \\
\hline \multicolumn{5}{|l|}{ Schistosoma species, $N(\%)$} \\
\hline S.haematobium & $49(47.6)$ & $46(46.9)$ & $3(60.0)$ & 0.102 \\
\hline S.mansoni & $48(46.6)$ & $46(46.9)$ & $2(40.0)$ & $0.037^{*}$ \\
\hline Both & $6(5.8)$ & $6(6.2)$ & $0(0.0)$ & \\
\hline Positive serology, N (\%) & $250(91.9)$ & $213(91.0)$ & $37(97.4)$ & 0.332 \\
\hline Increased lgE $\mathrm{E}^{\mathrm{C}}, N(\%)$ & $169(63.8)$ & $159(70.0)$ & $10(26.3)$ & $<0.001^{*}$ \\
\hline Blood eosinophilia, N (\%) & $130(47.8)$ & $115(49.1)$ & $15(39.5)$ & 0.297 \\
\hline Other helminths, $N(\%)$ & $49(22.8)$ & $44(18.8)$ & $5(13.2)$ & 0.499 \\
\hline Abnormal Ultrasound, N (\%) & $124(48.8)$ & $110(50.2)$ & $14(40.0)$ & 0.280 \\
\hline \multicolumn{5}{|l|}{ Infection Site, N (\%) } \\
\hline IS & $48(17.9)$ & $46(20.0)$ & $2(5.4)$ & $0.037^{*}$ \\
\hline HSS & $13(5.1)$ & $13(5.9)$ & $0(0)$ & \\
\hline UGS & $133(48.9)$ & $120(51.3)$ & $13(34.2)$ & 0.056 \\
\hline 1 & $110(43.8)$ & $88(40.6)$ & $22(64.7)$ & $0.009^{*}$ \\
\hline \multicolumn{5}{|l|}{ Diagnosis Type, N (\%) } \\
\hline Confirmed & $103(37.9)$ & $98(41.9)$ & $5(13.2)$ & $0.003^{*}$ \\
\hline Probable & $165(60.6)$ & $133(56.9)$ & $32(82.2)$ & \\
\hline Suspected & $4(1.5)$ & $3(1.2)$ & $1(2.6)$ & \\
\hline
\end{tabular}

Abbreviations: IS Intestinal, HSS Hepato-splenic schistosomiasis, UGS Urogenital schistosomiasis, I Indeterminate

${ }^{\text {a }}$ Relative frequencies for each variable are obtained on the sub-population for which information was available

${ }^{b}$ Calculation of the $P$-value was done through different statistical tests. Namely, Kolmogorov-Smirnov test was used for testing the difference in the distribution of age and elapsed time, whereas Fisher's exact test was used for all dichotomous variables. Finally, the Chi-Squared test was used to test the difference in the distribution among diagnoses

${ }^{\mathrm{C}}$ Total IgE value equal or above the upper normal limit $(\geq 120 \mathrm{IU} / \mathrm{ml})$

we relied on ova identification only, the number of cases diagnosed would have been much lower. On the other hand, we have recently shown that the sensitivity of ova detection is comparatively low [26]. It might be argued that a number of false positive cases may be comprised among those classified as "probable" on the basis of serology. However, the specificity of serology is high, and so is that of CCA test [26] hence the number of false positive cases (if any) is probably limited.

Almost half of the patients were asymptomatic. These data concur with other studies, reporting proportions ranging from 36 to $50 \%$, depending on the population analysed [36]. Coltart et al. described a more frequently asymptomatic presentation in the non-endemic group [35]: the most frequent symptom reported was abdominal pain and, although almost half of the cases were considered UGS, only $11 \%$ of the patients reported macroscopic haematuria. Differently from Coltart's work, several studies showed differences in clinical presentation between the endemic and the non-endemic groups. Lingscheid et al. found that Europeans presented more frequently fever and musculoskeletal symptoms, whereas 


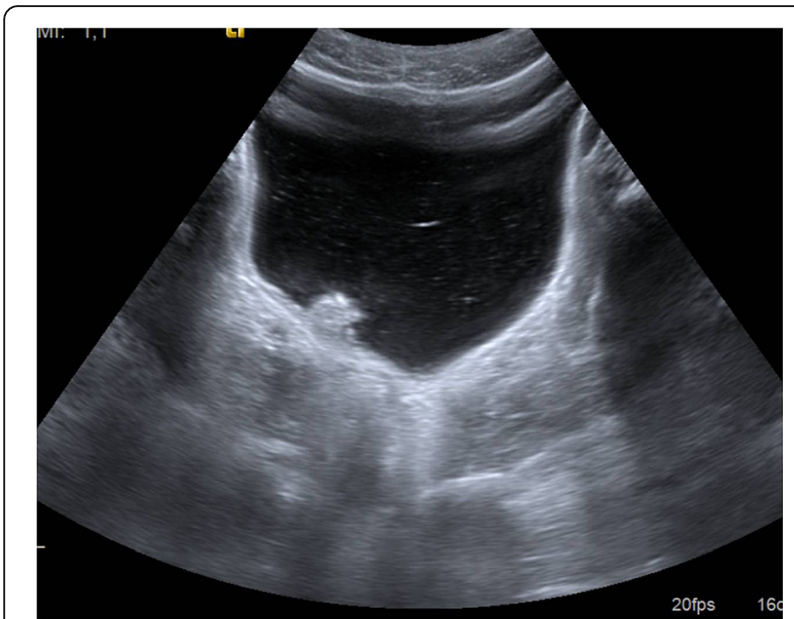

Fig. 2 Pseudopolyp of the urinary bladder in an immigrant with S. haematobium infection

the non-endemic group complained more often of haematuria, bloody diarrhoea and weight loss compatible with chronic schistosomiasis [36]. The high proportion of migrants in our series $(86 \%$, contrarily to other series in which the tourists represented the vast majority), along with the relatively long time elapsed from exposure to presentation to hospital of both groups (7 months in endemic and 4 months in non-endemic), probably accounts for the absence of febrile cases compatible with acute schistosomiasis [33, 34, 51]. Of note, a high proportion of cases had already developed symptoms/signs compatible with chronic schistosomiasis, and the treatment probably permitted to prevent life-threatening complications. However, almost half of the cases were asymptomatic, so this parasitic infection would have never be detected in this group if not systematically searched, based on epidemiological criteria.
Eosinophilia was present only in the $47.8 \%$ of the cases. Interestingly, a higher proportion (63.8\%) of subjects with increased IgE value was found, consistent with a recent study performed in an endemic area for $S$. mansoni [52]. In our study, some differences were found in the laboratory findings of the two main groups. In particular, a significantly higher proportion of patients with raised IgE was found in the endemic group.

The proportion of patients with positive serology was $92 \%$, whereas a confirmed parasitological diagnosis was achieved in $38 \%$ of patients; among the latter, 18 cases had negative serology. Worthy to note, the immunodiagnostic method was changed from IFAT to ELISA during the course of the study due to availability constraints. However, different studies showed similar sensitivity for the two tests, that is higher for $S$. mansoni infection $[53,54]$. Indeed, in our study, most of the 18 confirmed cases with negative serology (61\%) had S. haematobium infection, for which serology has sensitivity ranging from 21.4 to $71.4 \%$. [53].

In line with the literature, we considered only microscopy as gold standard for diagnosis [1]. The accuracy of CCA test for S.mansoni is not optimal, especially in case of urinary tract infections, hematuria, pregnancy and in young children [55]. Furthermore, the test was available only in the late stage of our study, and few results were available.

Abnormal US findings were present in about half of the study subjects. Hepatomegaly or splenomegaly was reported in 25.3 and $13.8 \%$ of cases, respectively, but of course this can be due to causes other than schistosomiasis. Therefore, abdominal organomegaly was not considered a sufficient criterion to define hepatosplenic schistosomiasis in our cohort. We then probably underestimated the proportion of HSS, especially in the early stage, which is most susceptible to regression after treatment.

Table 3 Crude and adjusted ORs for the association between patients' characteristics and the risk of detection of ova in any specimen ${ }^{\mathrm{a}}$

\begin{tabular}{|c|c|c|c|c|}
\hline Covariate $^{\text {b }}$ & Ova present & Ova absent & Crude $O R$ & Adjusted OR $(95 \% C l)^{c}$ \\
\hline Age & $26(21-32.5)$ & $34(27-44)$ & $0.93(0.90-0.95)$ & $0.94(0.91-0.97)$ \\
\hline Male & $91.3 \%$ & $71.0 \%$ & $4.22(1.92-10.31)$ & $2.04(0.78-5.81)$ \\
\hline Elapsed Time & $184(56-328)$ & $209(71-657)$ & 0.99 (0.99-0.99) & $1.00(0.99-1.01)$ \\
\hline Other Parasites & $18.4 \%$ & $17.5 \%$ & $1.06(0.53-2.11)$ & $0.79(0.36-1.70)$ \\
\hline Endemics & $95.2 \%$ & $80.7 \%$ & $4.66(1.72-15.87)$ & $2.08(0.64-8.10)$ \\
\hline Abnormal ultrasound & $61.0 \%$ & $41.0 \%$ & $2.23(1.30-3.89)$ & $2.12(1.15-3.96)$ \\
\hline Symptoms presence & $59.2 \%$ & $50.0 \%$ & $1.45(0.86-2.46)$ & $1.82(0.98-3.42)$ \\
\hline Increased lg $\mathrm{E}^{d}$ & $80.0 \%$ & $53.7 \%$ & $3.43(1.87-6.49)$ & $1.20(0.53-2.72)$ \\
\hline Blood eosinophilia & $64.0 \%$ & $37.3 \%$ & $2.98(1.74-5.15)$ & $1.98(1.03-3.83)$ \\
\hline
\end{tabular}

Abbreviations: $O R$ odds ratio, $\mathrm{Cl}$ confidence interval

a Due to the heterogeneity of provenience of patients, covariates such as exposure time could not be included in models

${ }^{b}$ Relative frequencies are presented here, whereas the median (interquartile range) is reported for Age and Elapsed Time

cAdjusted for every other covariate through a multivariate logistic regression model

${ }^{\mathrm{d}}$ Total IgE value equal or above the upper normal limit ( $\left.\geq 120 \mathrm{IU} / \mathrm{ml}\right)$ 
Differently, thick bladder wall and bladder lesions, both considered signs of $S$. haematobium infection, were found in 17.7 and $8.7 \%$ of the cases, respectively, and permitted to identify $20.5 \%$ patients with UGS.

No cases of liver or bladder cancer were found in our study.

The higher rate of US abnormalities found in patients with positive microscopy compared with patients with positive serology only is not surprising. Serology can detect a higher number of infections of low intensity, difficult to diagnose with stool/urine microscopy. Presumably, these are stages of infection that may still cause organ damage. Nevertheless, we cannot exclude some false positive results of serology, especially with regard to possible previous infections and treatments [56]. Assessing the efficacy (adequate dosage and duration) of previous treatments is challenging, and so is evaluating possible re-exposures occurred after treatment, particularly for migrants at first arrival. In consideration of the short-term treatment's high tolerability, it is worth treating subjects who are positive to serology only.

The association of ova identification with abnormal US findings and with blood eosinophilia (Table 3) is interesting, as it seems to suggest a correlation of these findings with the parasitic load. Neither finding, however, can be considered a good predictor or excluder of this infection, thus their clinical use is limited to potentially raising the index of suspicion, particularly in settings where accurate parasitological methods are not often accessible, and only a few (if any) immunodiagnostic methods are available.

On the other hand, we did not find any significant association between symptoms and ova detection, a factor which further supports the need for an active screening.

The association between younger age and positive microscopy confirms data already reported in the literature. Precisely, in endemic settings, people are often exposed to repeated infections during childhood and adolescence, and gradually develop an efficient immune response through time [52].

Our study has limitations, mainly due to its retrospective design. Firstly, we were not able to assess ova intensity in cases confirmed by microscopy, because these data had not been collected. Secondly, abdomen US had been performed following standard, clinical routine, which means that we might have missed initial forms of HSS or UGS. Finally, as mentioned above, the serological test for schistosomiasis was changed during the study period.

\section{Conclusions}

European clinicians need to be alerted about possible cases of schistosomiasis in subjects from endemic countries, particularly from sub-Saharan Africa.
The gold standard test permitted to diagnose only one-third of cases. Clinical and diagnostic presentation can be silent in patients with schistosomiasis. Symptoms, eosinophilia and abnormal US findings may raise the index of suspicion both in patients born in endemic and in non-endemic countries. The combination of different diagnostic tools may facilitate the diagnosis and allow the treatment of an infection that can lead to severe complications.

\section{Additional file}

Additional file 1: Multilingual abstracts in the five official working languages of the United Nations. (PDF 537 kb)

\section{Abbreviations}

AEC: Absolute eosinophils count; CCA: Cathodic circulating schistosomal antigen; Cl: Confidence interval; CTD: Centre for Tropical Diseases; ELISA: Enzyme-linked immunosorbent assay; HS: Hepatosplenic; HSS: Hepatosplenic schistosomiasis; IFAT: Indirect immunofluorescence; IQR: Inter-quartile range; IS: Intestinal schistosomiasis; NTD: Neglected tropical diseases; OR: Odds ratio; UG: Urogenital; UGS: Urogenital schistosomiasis; VFR: Visiting friends or relatives

\section{Acknowledgements}

The authors thank Maria Gobbo, Stefano Tais and Monica Degani, colleagues of the parasitology laboratory for their high-quality work. We are deeply grateful to Jessica Malzahn and Federico Formenti for language editing of the last version.

\section{Availability of data and materials}

The dataset used and analysed during the current study is available from the corresponding author on reasonable request.

\section{Authors' contributions}

Conceptualization: VM, AA, ZB. Data curation: VM, AB, GG. Formal analysis: GG. Investigation: VM, AA, AB, GM, FP. Methodology: ZB, AA. Project administration: VM, ZB. Resources: FP, DB. Supervision: ZB, AB, DB. Writing - original draft: VM, AB. Writing - review \& editing: VM, AB, AA, GM, GG, FP, ZB, DB. All authors read and approved the final manuscript.

\section{Ethics approval and consent to participate}

The study protocol received ethical approval and consent from the competent Ethics Committee (Comitato Etico per la sperimentazione Clinica delle Province di Verona e Rovigo) on the 16th May 2017 (protocol n 24 123). Each patient gave written informed consent to participate in the study and for the collection of data and biological samples for study purpose.

\section{Consent for publication}

Each patient gave written consent to publish ultrasound image.

\section{Competing interests}

The authors declare that they have no competing interests.

\section{Author details}

${ }^{1}$ Centre for Tropical Diseases, Sacro Cuore Don Calabria Hospital, Via Sempreboni 5, 37024 Negrar, Italy. ${ }^{2}$ University Department of Infectious and Tropical Diseases \& WHO Collaborating Centre for TB/HIV and TB elimination, University of Brescia, Piazzale Spedali Civili 1, 25123 Brescia, Italy.

Received: 5 October 2017 Accepted: 16 May 2018

Published online: 16 June 2018

References

1. Colley DG, Bustinduy AL, Secor WE, King CH. Human schistosomiasis. Lancet. 2014;383(9936):2253-64.

2. Murray CJ, Vos T, Lozano R, Naghavi M, Flaxman AD, Michaud C, et al. Disability-adjusted life years (DALYs) for 291 diseases and injuries in 21 
regions, 1990-2010: a systematic analysis for the global burden of disease study 2010. Lancet. 2012;380(9859):2197-223.

3. Hotez PJ, Alvarado M, Basanez MG, Bolliger I, Bourne R, Boussinesq M, et al. The global burden of disease study 2010: interpretation and implications for the neglected tropical diseases. PLoS Negl Trop Dis. 2014;8(7):e2865.

4. Schistosomiasis: number of people treated worldwide in 2014. Wkly Epidemiol Rec. 2016;91(5):53-60. (in English, French). Document available from http://www.who.int/wer/2016/wer9105.pdf?ua=1. Accessed May 2018.

5. Hotez PJ, Fenwick A. Schistosomiasis in Africa: an emerging tragedy in our new global health decade. PLoS Negl Trop Dis. 2009;3(9):e485.

6. Campbell SJ, Stothard JR, O'Halloran F, Sankey D, Durant T, Ombede DE, et al. Urogenital schistosomiasis and soil-transmitted helminthiasis (STH) in Cameroon: an epidemiological update at Barombi Mbo and Barombi Kotto crater lakes assessing prospects for intensified control interventions. Infect Dis Poverty. 2017;6(1):49.

7. Vonghachack Y, Sayasone S, Khieu V, Bergquist R, van Dam GJ, Hoekstra PT, et al. Comparison of novel and standard diagnostic tools for the detection of Schistosoma mekongi infection in Lao People's Democratic Republic and Cambodia. Infect Dis Poverty. 2017;6(1):127.

8. Chabasse D, Bertrand G, Leroux JP, Gauthey N, Hocquet P. Developmental bilharziasis caused by Schistosoma mansoni discovered 37 years after infestation. Bull Soc Pathol Exot Filiales. 1985;78(5):643-7. (in French)

9. Warren KS, Mahmoud AA, Cummings P, Murphy DJ, Houser HB. Schistosomiasis mansoni in Yemeni in California: duration of infection, presence of disease, therapeutic management. Am J Trop Med Hyg. 1974;23(5):902-9.

10. Whitty CJ, Mabey DC, Armstrong M, Wright SG, Chiodini PL. Presentation and outcome of 1107 cases of schistosomiasis from Africa diagnosed in a non-endemic country. Trans R Soc Trop Med Hyg. 2000;94(5):531-4.

11. Lambertucci JR, Serufo JC, Gerspacher-Lara R, Rayes AA, Teixeira R, Nobre V, et al. Schistosoma mansoni: assessment of morbidity before and after control. Acta Trop. 2000;77(1):101-9.

12. Khalaf I, Shokeir A, Shalaby M. Urologic complications of genitourinary schistosomiasis. World J Urol. 2012;30(1):31-8.

13. Richter J, Bode JG, Blondin D, Kircheis G, Kubitz R, Holtfreter MC, et al. Severe liver fibrosis caused by Schistosoma mansoni: management and treatment with a transjugular intrahepatic portosystemic shunt. Lancet Infect Dis. 2015;15(6):731-7.

14. IARC Working Group on the Evaluation of Carcinogenic Risks to Humans. Biological agents. Volume 100 B. A review of human carcinogens. IARC Monogr Eval Carcinog Risks Hum. 2012;100(Pt B):1-441.

15. Srougi V, Gallucci FP, Mattedi RL, Srougi M. Carcinosarcoma of the bladder following local schistosomiasis infection. BMJ Case Rep. 2017. https://doi. org/10.1136/bcr-2016-218642.

16. King $\mathrm{CH}$. It's time to dispel the myth of "asymptomatic" schistosomiasis. PLoS Negl Trop Dis. 2015;9(2):e0003504.

17. Trovato A, Reid A, Takarinda KC, Montaldo C, Decroo T, Owiti P, et al. Dangerous crossing: demographic and clinical features of rescued sea migrants seen in 2014 at an outpatient clinic at Augusta Harbor, Italy. Confl Health. 2016;10:14

18. McCarthy AE, Weld LH, Barnett ED, So H, Coyle C, Greenaway C, et al. Spectrum of illness in international migrants seen at GeoSentinel clinics in 1997-2009, part 2: migrants resettled internationally and evaluated for specific health concerns. Clin Infect Dis. 2013;56(7):925-33.

19. Ceccarelli G, d'Ettorre G, Riccardo F, Ceccarelli C, Chiaretti M, Picciarella A, et al. Urinary schistosomiasis in asylum seekers in Italy: an emergency currently undervalued. J Immigr Minor Health. 2013;15(4):846-50.

20. Serre Delcor N, Maruri BT, Arandes AS, Guiu IC, Essadik HO, Soley ME, et al. Infectious diseases in sub-Saharan immigrants to Spain. Am J Trop Med Hyg. 2016;94(4):750-6.

21. Beltrame A, Buonfrate D, Gobbi F, Angheben A, Marchese V, Monteiro GB, et al. The hidden epidemic of schistosomiasis in recent African immigrants and asylum seekers to Italy. Eur J Epidemiol. 2017 Aug;32(8):733-5.

22. Riccardi N, Nosenzo F, Peraldo F, Sarocchi F, Taramasso L, Traverso P, et al. Increasing prevalence of genitourinary schistosomiasis in Europe in the migrant era: neglected no more? PLoS Negl Trop Dis. 2017;11(3):e0005237.

23. Infurnari L, Galli L, Bigoloni A, Carbone A, Chiappetta S, Sala A, et al. The use of circulating cathodic antigen rapid test and serology for diagnosis of active Schistosoma mansoni infection in migrants in Italy, a non-endemic country: a cross sectional study. Mem Inst Oswaldo Cruz. 2017;112(6):452-5.

24. Chernet A, Kling K, Sydow V, Kuenzli E, Hatz C, Utzinger J, et al. Accuracy of diagnostic tests for Schistosoma mansoni infection in asymptomatic Eritrean refugees: serology and POC-CCA against stool microscopy. Clin Infect Dis. 2017;65(4):568-74.

25. Theuring S, Friedrich-Janicke B, Portner K, Trebesch I, Durst A, Dieckmann S, et al. Screening for infectious diseases among unaccompanied minor refugees in berlin, 2014-2015. Eur J Epidemiol. 2016;31(7):707-10.

26. Beltrame A, Guerriero M, Angheben A, Gobbi F, Requena-Mendez A, Zammarchi $L$, et al. Accuracy of parasitological and immunological tests for the screening of human schistosomiasis in immigrants and refugees from African countries: an approach with latent class analysis. PLoS Negl Trop Dis. 2017;11(6):e0005593.

27. Schlagenhauf $P$, Weld L, Goorhuis A, Gautret P, Weber R, von Sonnenburg F, et al. Travel-associated infection presenting in Europe (2008-12): an analysis of EuroTravNet longitudinal, surveillance data, and evaluation of the effect of the pre-travel consultation. Lancet Infect Dis. 2015;15(1):55-64.

28. Visser LG, Polderman AM, Stuiver PC. Outbreak of schistosomiasis among travelers returning from Mali, West Africa. Clin Infect Dis. 1995;20(2):280-5.

29. Amorosa V, Kremens D, Wolfe MS, Flanigan T, Cahill KM, Judy K, et al. Schistosoma mansoni in family 5 years after safari. Emerg Infect Dis. 2005;11(2):339-41.

30. Jelinek T, Nothdurft HD, Loscher T. Schistosomiasis in travelers and expatriates. J Travel Med. 1996;3(3):160-4.

31. Roca C, Balanzo X, Gascon J, Fernandez-Roure JL, Vinuesa T, Valls ME, et al. Comparative, clinico-epidemiologic study of Schistosoma mansoni infections in travellers and immigrants in Spain. Eur J Clin Microbiol Infect Dis. 2002;21(3):219-23.

32. Grobusch MP, Muhlberger N, Jelinek T, Bisoffi Z, Corachan M, Harms G, et al. Imported schistosomiasis in Europe: sentinel surveillance data from TropNetEurop. J Travel Med. 2003;10(3):164-9.

33. Bierman WF, Wetsteyn JC, van Gool T. Presentation and diagnosis of imported schistosomiasis: relevance of eosinophilia, microscopy for ova, and serology. J Travel Med. 2005;12(1):9-13.

34. Nicolls DJ, Weld LH, Schwartz E, Reed C, von Sonnenburg F, Freedman DO, et al. Characteristics of schistosomiasis in travelers reported to the GeoSentinel surveillance network 1997-2008. Am J Trop Med Hyg. 2008; 79(5):729-34.

35. Coltart CE, Chew A, Storrar N, Armstrong M, Suff N, Morris L, et al. Schistosomiasis presenting in travellers: a 15 year observational study at the Hospital for Tropical Diseases, London. Trans R Soc Trop Med Hyg. 2015;109(3):214-20.

36. Lingscheid T, Kurth F, Clerinx J, Marocco S, Trevino B, Schunk M, et al. Schistosomiasis in European travelers and migrants: analysis of 14 years TropNet surveillance data. Am J Trop Med Hyg. 2017;97(2):567-74.

37. Beltrame A, Zammarchi L, Zuglian G, Gobbi F, Angheben A, Marchese V, et al. Schistosomiasis screening of travelers to Corsica, France. Emerg Infect Dis. 2016;22(1):159-60.

38. Berry A, Fillaux J, Martin-Blondel G, Boissier J, Iriart X, Marchou B, et al. Evidence for a permanent presence of schistosomiasis in Corsica, France, 2015. Euro Surveill. 2016;21(1). https://doi.org/10.2807/1560-7917.

39. Mone $\mathrm{H}$, Holtfreter MC, Allienne JF, Mintsa-Nguema R, Ibikounle M, Boissier J, et al. Introgressive hybridizations of Schistosoma haematobium by Schistosoma bovis at the origin of the first case report of schistosomiasis in Corsica (France, Europe). Parasitol Res. 2015;114(11):4127-33.

40. Boissier J, Grech-Angelini S, Webster BL, Allienne JF, Huyse T, Mas-Coma S, et al. Outbreak of urogenital schistosomiasis in Corsica (France): an epidemiological case study. Lancet Infect Dis. 2016;16(8):971-9.

41. Boissier J, Mone H, Mitta G, Bargues MD, Molyneux D, Mas-Coma S. Schistosomiasis reaches Europe. Lancet Infect Dis. 2015;15(7):757-8.

42. Gautret $P$, Mockenhaupt FP, Bottieau E, Parola P, Schistosomiasis in Corsica SP. The pivotal role of travellers. Lancet Infect Dis. 2015;15(12):1378-9.

43. Bisoffi Z, Buonfrate D, Beltrame A. Schistosomiasis transmission in Europe. Lancet Infect Dis. 2016;16(8):878-80.

44. Kincaid-Smith J, Rey O, Toulza E, Berry A, Boissier J. Emerging schistosomiasis in Europe: a need to quantify the risks. Trends Parasitol. 2017;33(8):600-9.

45. de Laval F, Savini H, Biance-Valero E, Simon F. Human schistosomiasis: an emerging threat for Europe. Lancet. 2014;384(9948):1094-5.

46. Buonfrate D, Perandin F, Formenti F, Bisoffi Z. A retrospective study comparing agar plate culture, indirect immunofluorescence and real-time PCR for the diagnosis of Strongyloides stercoralis infection. Parasitology. 2017; 144(6):812-6.

47. Cerri GG, Alves VA, Magalhaes A. Hepatosplenic schistosomiasis mansoni: ultrasound manifestations. Radiology. 1984;153(3):777-80. 
48. Aliotta Antonio FG, Livraghi Tito. Standard per una corretta esecuzione dell'esame ecografico. J Ultrasound Giornale Italiano di Ecografia. 2009;speciale 7-8. (in italian).

49. Akpata R, Neumayr A, Holtfreter MC, Krantz I, Singh DD, Mota R, et al. The WHO ultrasonography protocol for assessing morbidity due to Schistosoma haematobium. Acceptance and evolution over 14 years. Systematic review. Parasitol Res. 2015;114(4):1279-89.

50. Team RC. R: a language and environment for statistical computing. Vienna: R Foundation for Statistical Computing; 2017.

51. Meltzer E, Artom G, Marva E, Assous MV, Rahav G, Schwartzt E. Schistosomiasis among travelers: new aspects of an old disease. Emerg Infect Dis. 2006;12(11):1696-700.

52. Elfaki TE, Arndts K, Wiszniewsky A, Ritter M, Goreish IA, Atti El Mekki Mel Y, et al. Multivariable regression analysis in Schistosoma mansoni-infected individuals in the Sudan reveals unique immunoepidemiological profiles in uninfected, egg+ and non-egg+ infected individuals. PLoS Negl Trop Dis. 2016;10(5):e0004629.

53. Kinkel HF, Dittrich S, Baumer B, Weitzel T. Evaluation of eight serological tests for diagnosis of imported schistosomiasis. Clin Vaccine Immunol. 2012;19(6):948-53.

54. Azab ME, Safer EH, Ghaffar FM. An IFAT cercarial slide antigen preparation for schistosomiasis. Folia parasitological. 1984;31(1):93-6.

55. Chernet A, Kling K, Sydow V, Kuenzli E, Hatz C, Utzinger J, et al. Accuracy of diagnostic tests for Schistosoma mansoni infection in asymptomatic Eritrean refugees: serology and point-of-care circulating cathodic antigen against stool microscopy. Clin Infect Dis. 2017;65(4):568-74.

56. Hinz R, Schwarz NG, Hahn A, Frickmann H. Serological approaches for the diagnosis of schistosomiasis: a review. Mol Cell Probes. 2017;31:2-21.

Ready to submit your research? Choose BMC and benefit from:

- fast, convenient online submission

- thorough peer review by experienced researchers in your field

- rapid publication on acceptance

- support for research data, including large and complex data types

- gold Open Access which fosters wider collaboration and increased citations

- maximum visibility for your research: over $100 \mathrm{M}$ website views per year

At BMC, research is always in progress.

Learn more biomedcentral.com/submissions 